\title{
EFISIENSI KAPASITAS LENTUR BETON PRACETAK (U-DITCH) DENGAN MODEL DINDING CORRUGATED
}

\author{
Erwin Syaiful Wagola *1, Muhammad Tharik Kemal ${ }^{2}$ \\ ${ }^{1}$ Dosen / Program Studi Teknik Sipil / Fakultas Teknik / Universitas Iqra Buru \\ ${ }^{2}$ Dosen / Program Studi Teknik Industri / Fakultas Teknik / Universitas Iqra Buru \\ Korespondensi: syaifulpasca14@gmail.com
}

\begin{abstract}
This study discusses to analyze the flexural capacity and efficiency of the corrugated U-Ditch type with dimensions of $50 \times 50 \mathrm{~cm}$ to the normal U-Ditch type. In this research using JIS (Japan International Standard) method for The U-Ditch Corrugated test. The results showed that the flexural behavior of the Normal Type UDitch is linear to collapse with a crack pattern occurring on the U-Ditch wall. The bending of the U-Ditch Corrugated type tends to be linear until it collapses with a crack pattern occurring in the structural wall. The magnitude of the bending moment capacity for the normal type is $9.11 \mathrm{kN.m}$ and capacity of the U-Ditch corrugated type is $8.05 \mathrm{kN}$. $m$ where the efficiency of bending capacity is $98 \%$.
\end{abstract}

Keywords: U-Ditch, Corrugated, Eficiency Of the corrugated

\section{PENDAHULUAN}

Pada jalan-jalan utama di kota besar di Indonesia saat ini banyak digunakan U-Ditch dengan tipe $80 \times 80 \mathrm{~cm}$. yang menjadi permasalahan adalah U-Ditch di Indonesia belum didesain sesuai dengan beban yang akan dipikul, sehingga perlu dilakukan kajian terhadap kapasitas lentur dari U-Ditch itu sendiri. U-Ditch beton bertulang merupakan salah satu inovasi dari beton pracetak yang diperuntukan sebagai saluran, baik untuk saluran drainase maupun saluran irigasi. Ketinggian saluran terbuka ini dapat bervariasi mengikuti kebutuhan di lapangan atau elevasi saluran yang diinginkan [1]. Suatu Beton pracetak yang diproduksi secara baik menggunakan standar akan menghasilkan suatu sistem konstruksi yang memiliki ketahanan yang baik [2]. Beberapa elemen pracetak bahkan telah dikembangkan untuk elemen-elemen struktur yang penting untuk menjamin durabilitasnya seperti untuk sistem sambungan [3].

Di beberapa negara maju seperti Jepang, penggunakan U-Ditch pracetak telah menjadi standar konstruksi untuk drainase. Standar yang baku telah dikembangkan untuk menjamin kualitas produk dan konstruksi. Dengan adanya standar baku, maka keragaman kualitas produk dan kualitas konstruksi tidak terjadi. Industri pracetak di Jepang telah dilengkapi oleh berbagai standar [4]. Di Indonesia sistem struktur beton bertulang sedang mengalami perkembangan yang pesat, walaupun masih terbatas pada stuktur-struktur tertentu yang telah memiliki standar seperti untuk struktur gedung [3]. Beberapa elemen pracetak bahkan telah dikembangkan untuk elemen-elemen struktur yang penting untuk menjamin durabilitasnya seperti untuk sistem sambungan [5].

Dengan melihat persoalan di atas maka dibuatkah prototipe saluran yang lebih efektif, efisien, dan ekonomis dengan tipe dinding Corrugated berukuran $50 \times 50 \mathrm{~cm}$, yang memiliki kekuatan tinggi terhadap beban lentur.

Adapun batasan masalah dalam penelitian ini adalah sebagai berikut :

1. Bagaimana Kapasitas Lentur beton pracetak (U-Ditch) tipe Corrugated tanpa FRP dan yang menggunakan FRP.

2. Bagaimana Efisiensi Kapasitas Lentur (EKL) dari beton pracetak (U-Ditch) tipe Corrugated.

Tujuan dari pada Penelitian ini adalah Menganalisis Kapasitas Lentur beton pracetak (U-Ditch) tipe Corrugated tanpa FRP dan yang menggunakan FRP, dan Menentukan besarnya 
Efisiensi Kapasitas Lentur (EKL) dari beton pracetak (U-Ditch) tipe Corrugated.

\section{METODOE PENELITIAN}

\subsection{Desain Benda Uji}

Disain dari beton pracetak U-Ditch yang dibuat dan akan uji dalam penelitian ini, terdiri dari tiga variasi benda uji yaitu, benda uji normal, benda uji dengan dinding Corrugated, dan benda uji dinding Corrugated yang diperkuat oleh lembar FRP. Adapun dimensi dari ketiga benda uji ini akan dibuat seragam dengan ukuran 500 × $500 \times 1000 \mathrm{~mm}$, dengan ketebalan dinding bagian atas $60 \mathrm{~mm}$, dinding bawah $70 \mathrm{~mm}$ dan tebal pelat injak $70 \mathrm{~mm}$. adapun prototype dari benda uji Corrugated dapat dilihat pada Gambar 1, Gambar 2 dan Gambar 3.

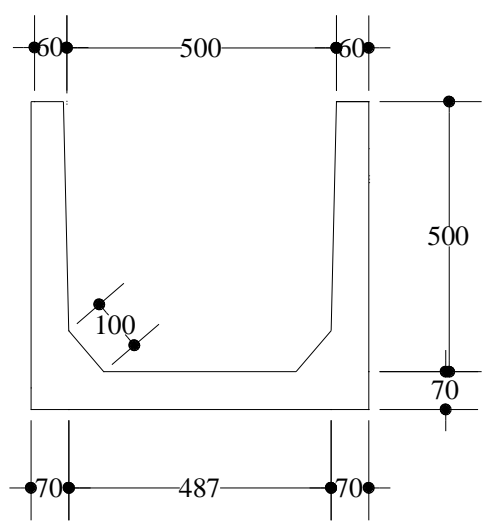

Gambar 1. Tampak Depan U-Ditch Corrugated

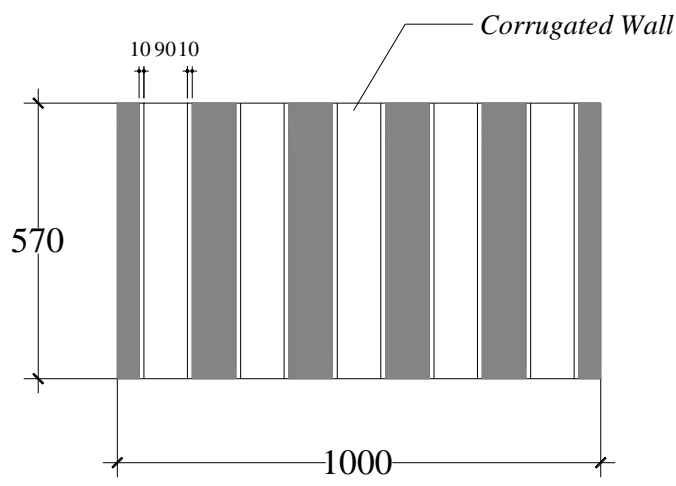

Gambar 2. Tampak Samping Ditch Corrugated Tanpa Perkuatan FRP

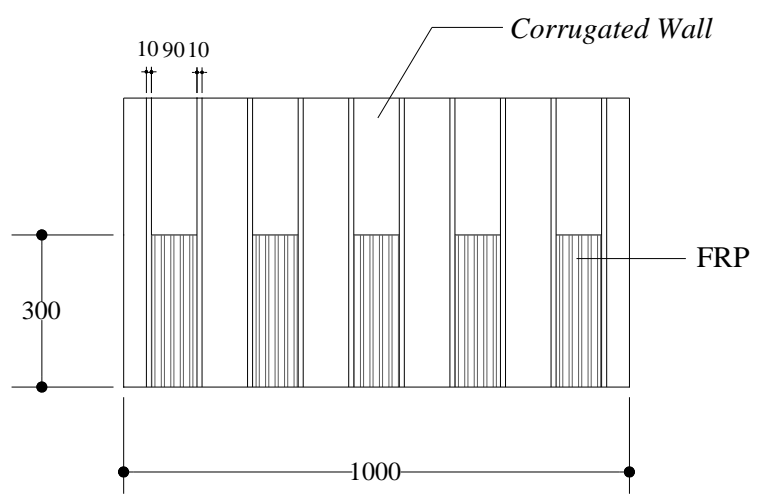

Gambar 3. Disain Benda Uji Inovasi Tipe Corrugated Dengan Perkuatan FRP

\subsection{Metode Pengetesan Benda Uji}

Dalam pengujian terhadap benda uji UDitch tipe Corrugated, akan digunakan model pembebanan yang mengacu pada standar pengujian U-Ditch di Jepang yakni (JIS A 5363) [6]. Ada pun set up pengujian untuk beton pracetak U-Ditch tipe Corrugated diperlihatkan pada Gambar 4 di bawah ini:

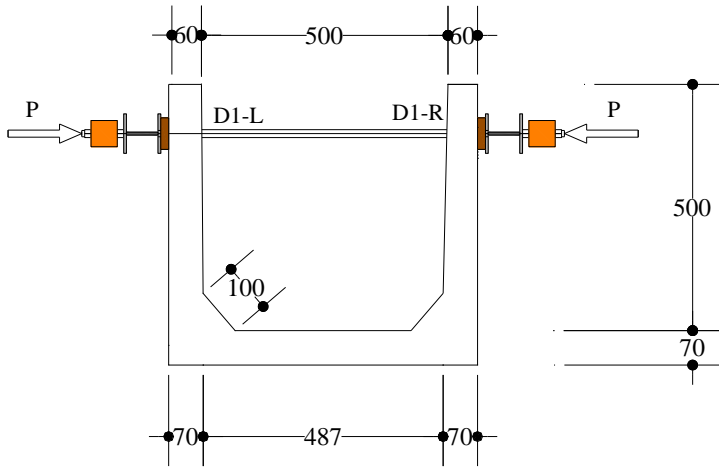

Gambar 4. Set Up Pengujian Benda Uji [6]

\section{HASIL DAN PEMBAHASAN \\ 3.1. Karakteristik Bahan}

Hasil pengujiian karakteristik bahan terdiri dari uji tarik baja, dan uji karakteristik beton. Adapun hasil uji tarik baja dan karakteristik beton diperlihatkan pada Tabel 1 dan Tabel 2. 
Tabel 1. Hasil Uji Kuat Tarik Baja

\begin{tabular}{ccccc}
\hline No. & $\begin{array}{c}\text { Diameter } \\
(\mathrm{mm})\end{array}$ & $\begin{array}{c}\text { fy } \\
(\mathrm{Mpa})\end{array}$ & $\begin{array}{c}\text { fmax } \\
(\mathrm{Mpa})\end{array}$ & $\begin{array}{c}\text { Es } \\
(\mathrm{Mpa})\end{array}$ \\
\hline 1 & D10 & 634 & 665 & \\
2 & $\varnothing 8$ & 342 & 468 & \\
\hline
\end{tabular}

Tabel 2. Hasil uji karakteristik beton

\begin{tabular}{cccc}
$\begin{array}{c}\text { No. } \\
\text { Sampel }\end{array}$ & $\begin{array}{c}\text { Berat } \\
(\mathrm{kg})\end{array}$ & $\begin{array}{c}\text { Kuat } \\
\text { Tekan } \\
(\mathrm{Mpa})\end{array}$ & $\begin{array}{c}\text { Modulus } \\
\text { Elastisitas } \\
(\mathrm{Mpa})\end{array}$ \\
\hline 1 & 3.545 & $* 24$ & \\
2 & 3.555 & $* 25$ & \\
3 & 3.555 & 29 & \\
4 & 3.575 & 28 & 25875 \\
5 & 3.550 & 34 & \\
6 & 3.460 & 31 & \\
7 & 3.495 & 31 & \\
8 & 3.445 & 29 & \\
Rata-rata & & 30 & \\
\hline * tidak dimasukkan dalam perhitungan rata-rata
\end{tabular}

* tidak dimasukkan dalam perhitungan rata-rata

\subsection{Rasio Kapasitas Lentur Beton U-Ditch terhadap berat struktur}

Adapun hasil analisis pengujian Kapasitas lentur dari Beton Pracetak U-Ditch tipe normal dan tipe Corrugated terhadap berat struktur diperlihatkan pada Tabel 3.

\subsection{Efisiensi Kapasitas Lentur}

Hasil analisa yang dilakukan memperlihatkan bahwa rasio perbandingan kapasitas momen U-Ditch Tipe Corrugated per ton per $\mathrm{M}$ ' terhadap kapasitas lentur U-Ditch tipe normal, menghasilkan suatu nilai Efisiensi Kapasitas Lentur (EKL) dari U-Ditch tipe Corrugated terhadap U-Ditch tipe normal sebesar sekitar 98\%. Dan disini terlihat bahwa meskipun ringan tapi U-Ditch tipe Corrugated mampu memberikan kontribusi kapasitas lentur yang cukup besar yang hampir mendekati kapasitas lentur U-Ditch tipe normal. Adapun rasio perbandingan kapasitas lentur per ton per
M' dari U-Ditch Tipe Corrugated terhadap UDitch tipe normal diperlihatkan pada Gambar 5.

Tabel 3. Rekapitulasi Kapasitas Lentur

\begin{tabular}{|c|c|c|c|c|}
\hline \multirow{2}{*}{$\begin{array}{c}\text { Tipe } \\
U \text {-Ditch }\end{array}$} & \multirow{2}{*}{$\begin{array}{l}\text { Berat } \\
\text { per M' } \\
(\mathrm{kg})\end{array}$} & \multirow{2}{*}{$\begin{array}{c}\text { Beban } \\
\text { Maksi } \\
\text { mum } \\
(\mathrm{kN})\end{array}$} & \multicolumn{2}{|c|}{$\begin{array}{c}\text { Kapasitas } \\
\text { Momen } \\
\text { Lentur (kN.m) }\end{array}$} \\
\hline & & & $\begin{array}{l}\text { Per } \\
\text { M' }^{\prime}\end{array}$ & $\begin{array}{l}\text { Per } \\
\text { Berat } \\
\text { (t) }\end{array}$ \\
\hline Normal 1 & \multirow[b]{2}{*}{271.65} & 25.84 & 9.04 & 33.29 \\
\hline \multirow[t]{2}{*}{ Normal 2} & & 26.24 & 9.18 & 33.80 \\
\hline & & Rata-rata & 9.11 & 33.55 \\
\hline Corrugated & \multirow{3}{*}{244.29} & 22.16 & 7.76 & 31.76 \\
\hline $\begin{array}{c}\text { Corrugated } \\
+ \text { FRP }\end{array}$ & & 23.83 & 8.34 & 34.15 \\
\hline & & Rata-rata & 8.05 & 32.95 \\
\hline
\end{tabular}

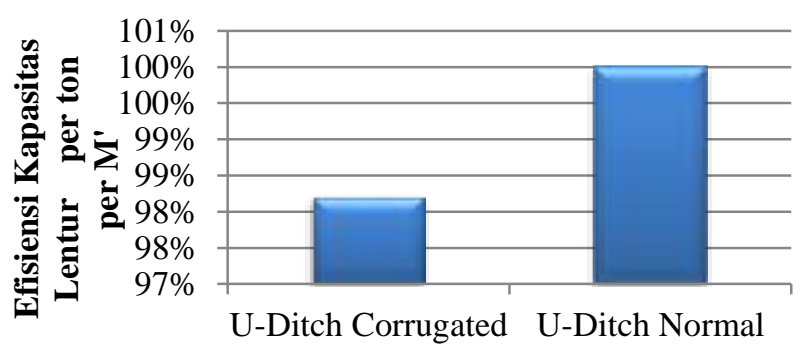

Gambar 5. Rasio Perbandingan Kapasitas Lentur

\subsection{Perilaku Lentur Beton Pracetak U-Ditch 3.4.1. Perilaku Lentur Beton Pracetak U- Ditch Tipe Normal \\ Gambar 6 memperlihatkan hubungan} beban dan lendutan pada beton pracetak U-Ditch tipe Normal sampel 1 dengan pembebanan berdasarkan standar JIS A 5363) [6], dimana retak awal pada beton terjadi pada beban sebesar $15.85 \mathrm{kN}$ dengan besar lendutan $7.26 \mathrm{~mm}$. dimana retakan yang terjadi terkonsentrasi pada dinding saluran. Dimana grafik memperlihatkan periaku dari struktur cenderung bersifat elastis hingga beban ultimit tercapai, Dimana sejalan dengan bertambahnya perilaku struktur tetap cenderung linier hingga mencapai beban maksimum sebesar $25.84 \mathrm{kN}$ dengan lendutan sebesar $13.41 \mathrm{~mm}$. Terlihat struktur cukup kaku 
karena lendutan saat maksimum belum mencapai nilai yang ditargetkan yakni $20 \mathrm{~mm}$.

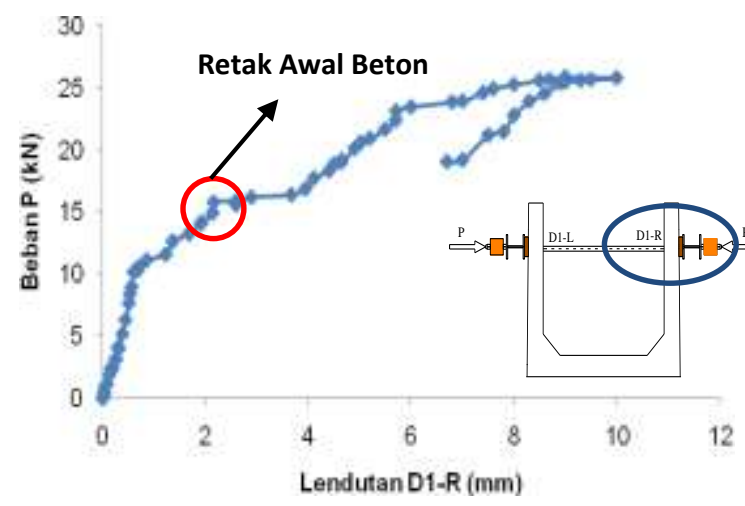

Gambar 6. Grafik Hubungan Beban dan Lendutan $U$-Ditch Tipe Normal-1

\subsubsection{Perilaku Lentur Beton Pracetak U- Ditch Tipe Corrugated Tanpa Perkuatan FRP}

Perilaku lentur beton pracetak U-Ditch Inovasi tipe Corrugated tanpa perkuatan FRP memperlihatkan perilaku struktur dimana retak awal pada beton terjadi pada beban sebesar $12.15 \mathrm{kN}$ dengan besar lendutan $3.67 \mathrm{~mm}$. dimana retakan yang terjadi terkonsentrasi pada dinding saluran. Pada Gambar 7, grafik trlihat pertambahan beban cenderung belinier hingga beban ultimit. Kondisi ultimit tercapai pada beban sebesar $22.16 \mathrm{kN}$ dengan lendutan sebesar $12.04 \mathrm{~mm}$.

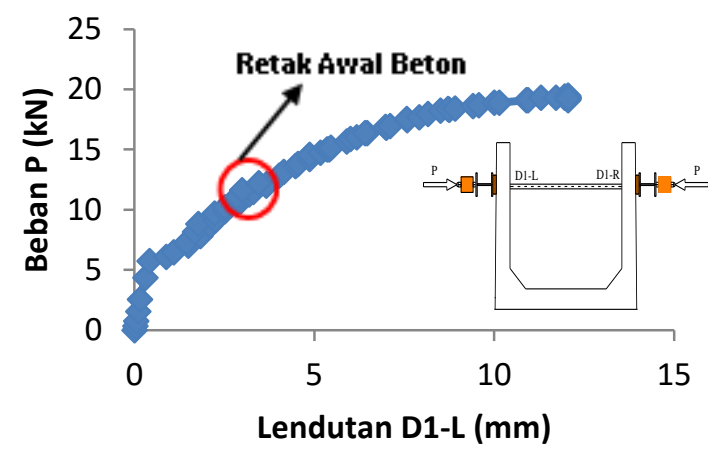

Gambar 7. Grafik Hubungan Beban dan Lendutan U-Ditch Tipe Corrugated Tanpa Perkuatan FRP

\subsubsection{Perilaku Lentur Beton Pracetak U- Ditch Tipe Corrugated dengan Perkuatan FRP \\ Gambar 8 memperlihatkan perilaku lentur dari U-Ditch tipe Corrugated dengan}

perkuatan FRP dimana retak awal pada beton terjadi pada beban sebesar $12.15 \mathrm{kN}$ dengan besar lendutan $0.84 \mathrm{~mm}$. dimana retakan yang terjadi terkonsentrasi pada dinding saluran. Pada grafik trlihat pertambahan beban cenderung belinier hingga beban ultimit. Kondisi ultimit tercapai pada beban sebesar $23.83 \mathrm{kN}$ dengan lendutan sebesar $6.23 \mathrm{~mm}$. disini terlihat bahwa U-Ditch tipe Corrugated dengan perkuatan FRP cenderung lebih kaku dari U-Ditch tipe Corrugated tanpa perkuatan.

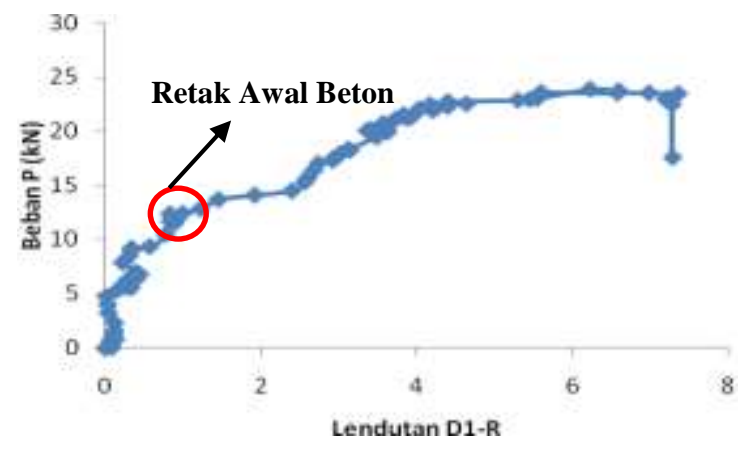

Gambar 8. Grafik Hubungan Beban dan Lendutan U-Ditch Inovasi Tipe Corrugated Dengan Perkuatan FRP

\section{KESIMPULAN DAN SARAN \\ 4.1 Kesimpulan}

Berdasarkan hasil analisis yang dilakukan maka diperoleh :

1. Kapasitas momen lentur rata-rata untuk UDitch tipe Normal adalah 9.11 kN.m, dan untuk U-Ditch tipe Corrugated adalah 8.05 kN.m,

2. Rasio perbandingan kapasitas momen UDitch tipe Corrugated per ton per M' terhadap kapasitas lentur U-Ditch tipe Normal, memiliki Efisiensi Kapasitas Lentur (EKL) sebesar 98\%.

\subsection{Saran}

Berdasarkan hasil eksperimen yang telah dilakukan maka dapat disarankan beberapa hal yaitu :

1. Produk beton pracetak (U-Ditch) tipe Corrugated, memiliki disain dan sistem penulangan sudah sesuai standar. Sehingga dapat diproduksi secara luas untuk pasaran.

2. Untuk mencapai hasil yang maksimal perlu diperhatikan presisi dari pengerjaan mulai 
dari perakitan, pengecoran hingga pengetesan

\section{DAFTAR PUSTAKA}

[1] Erwin Syaiful Wagola, at. all. (2017), "Kapasitas Lentur Sluran Drainase Pracetak U Ditch" Jurnal Sains \& Teknologi Vol. 6 No. 1 ISSN 2303-3614. Hal. 1-103.

[2] Elliott K. (2002), "Precast Concrete Structures", Butterwoth-Heinemann.
[3] SNI-03-2847-2002, "Tata Cara Perhitungan Struktur Beton Untuk Bangunan Gedung”..

[4] Japan International Standard, "General rules for methods of performance test”, JIS A 5363.

[5] Rohit B., Nimse., Digesh D., Joshi \& Patel P.V. (2014), "Behavior of wet precast beam column connectionsunder progressive collapse scenario: an experimental study", Int J Adv

[6] Japan International Standard, "Reinforced concrete gutters for roadside”, JIS A 5345. 